\title{
Approximate Analysis of Discrete-Time Tandem Queueing Networks with Customer Loss
}

Dooyeong Park

Harry G. Perros

Center for Communications and Signal Processing Department of Computer Science North Carolina State University

\author{
TR-91/20 \\ December 1991
}




\title{
Approximate Analysis of Discrete-time Tandem Queueing Networks with Customer Loss*
}

\author{
Dooyeong Park \\ Department of Eletrical and Computer Engineering, and \\ Center for Communications and Signal Processing \\ North Carolina State University \\ Raleigh, NC 27695 \\ Harry G. Perros \\ Department of Computer Science, and \\ Center for Communications and Signal Processing \\ North Carolina State University \\ Raleigh, NC 27695
}

Abstract. We first approximate the departure process of an IBP/Geo/1/K queue by an Interrupted Bernoulli Process (IBP). We consider several different approximation models and their accuracy is examined through extensive validation tests. These models are then used in a simple decomposition algorithm to analyze a tandem configuration of finite capacity queues with customer loss. The decomposition algorithm is validated by comparing it against simulation and it is shown to have a good accuracy.

- Supported in part by IBM under grant no. 1116 from the Network Analysis Center, IBM Research Triangle Park, and by DARPA under grant no. DAEA 18-90-c-0039 


\section{Introduction}

In recent years there has been a lot of interest in the development of high-speed communication networks. The most promising design for high-speed networks is the Asynchronous Transfer Mode (ATM). The need for performance evaluation of ATM networks has given rise to a widespread interest for the analysis of discrete-time queueing systems. Discrete-time single server queues with or without finite capacity have been extensively analyzed. For a review of relevant results see Pujolle and Perros [10]. However, little has been done for the analysis of networks of discrete-time finite capacity queues.

A network of discrete-time finite capacity queues can be used to model the queueing within an ATM switch, or the queueing within a network of ATM switches. Two different assumptions can be made regarding such a network:(1) A customer gets lost when it arrives to a full queue.(2) A customer cannot start its service until there is space in the destination queue. This is similar to the blocking-before-service mechanism that has been extensively studied in continuous-time queueing networks of finite capacity queues. In telecommunication systems, this mechanism is often referred to as back pressure.

The external arrival process to the network is assumed to be bursty. Typically, a bursty arrival process is represented by an Interrupted Bernoulli Process (IBP). In an IBP, we have a geometrically distributed period during which no arrivals occur, followed by a geometrically distributed period during which arrivals occur in a Bernoulli fashion. The IBP is a special case of the Markov Modulated Bernoulli Process (MMBP), which has a slightly more complex structure and it captures the notion of the burstiness and the correlation of successive interarrival times.

In this paper, we analyze a tandem queueing network of discrete-time finite capacity queues with customer loss. The arrival process to the first queues is assumed to be an IBP. The service times at each queue are assumed to be geometrically distributed. The choice of the geometric distribution was motivated by ATM networks. In general, a service time represents a transmission time. In an ATM network the size of a packet (commonly known 
as cell) is constant, and therefore the transmission time is constant as well. However, in some ATM switch architectures a cell may be re-transmitted several times due to possible collisions with other cells. In this case, the total transmission time is typically modelled by a geometric distribution. Queueing networks of discrete-time finite capacity queues with customer loss do not lend themselves to an exact analysis. However, they can be analyzed approximately using the notion of decomposition. That is, the network is decomposed into individual queues, and each queue is then analyzed separately. The most important aspect of such a decomposition is the characterization of the arrival process to an intermediate queue. In continuous-time queueing networks, typically, such as an arrival process is characterized approximately by a two-phased Coxian distribution, or by a more general phased-type distribution. Also, it has been characterized by a general distribution defined by the mean and squared coefficient of variation. In this paper, the departure process from one queue, which becomes the arrival process to the next downstream queue is characterized approximately by an IBP. Various fitting models, motivated by the method of moments, are examined and compared. These models are then used in the approximate analysis of a tandem queueing network with discrete-time finite capacity queues.

The interdeparture distribution of a discrete-time GI/G/1 queue has been obtained by Tran-Gia [11] using the Fast Fourier Transform. He also derived the idle period distribution from the equilibrium distribution of the virtual unfinished work. Ohba, Murata and Miyahara [8] analyzed a discrete-time single-server queue with the following three arrival streams: 1) arrivals with a general interdeparture time distribution, 2) Bernoulli arrivals in batches, and 3) IBP. Discrete-time queueing networks have been analyzed by Morrison [6], Hsu and Burke [3], Ohba, Murata, and Miyahara [8] and Pujolle [9] assuming infinite capacity queues. Bhargava et al [1] and Bocharov and Albores [2] analyzed tandem configurations of finite capacity queues with customer loss, but in continuous-time. Finally, Morris and Perros [5] analyzed an ATM switch architecture, which basically involved the analysis of a discrete-time tandem configuration of finite capacity queues with blocking-before-service.

This paper is organized as follows. In section 2, we give a brief description of an IBP. 


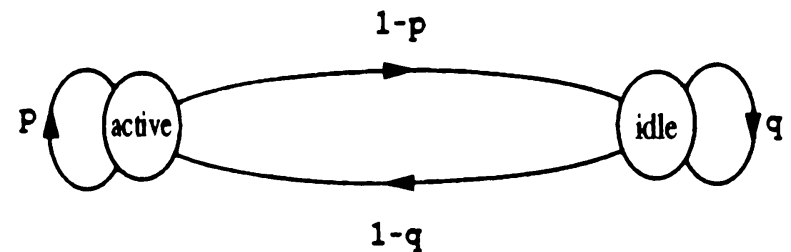

Figure 1: The Markov chain for an IBP

The generating function of the interdeparture time of an IBP/Geo/1/K queue is obtained in section 3. In section 4, we present various fitting models for characterizing the departure process as an IBP and examine their accuracy. In section 5 , we analyze a tandem configuration of finite capacity queues with cell loss using some of the approximation models obtained in section 4 . The approximate results are compared against simulation in section 5 , and conclusions are given in section 6 . We note that in accordance with the terminology of ATM networks, we shall refer to a customer as a cell.

\section{The Interrupted Bernoulli Process}

The Interrupted Bernoulli Process (IBP) is defined over a slotted (discrete-time) time axis and it comprises two states, an active state and an idle state, which alternate. The time the process spends in each state is geometrically distributed. Arrivals occur in a Bernoulli fashion when the process is in the active state. No arrival occurs if the process is in the idle state. Given that the process is in the active state (or idle state) at slot $i$, it will remain in the same state in the next slot $i+1$ with probability $p$ (or $q$ ), or will change to the idle state (or active state) with probability $1-p$ (or $1-q$ ). The transitions between the active and idle states are governed by a two state Markov chain as shown in Figure 1. During the active state, a slot contains a cell with probability $\alpha . \alpha=1$ means that every busy slot contains a cell.

Let $t$ be the interarrival time of a cell. It can be shown that the mean interarrival time, $E\{t\}$ and the squared coefficient of variation of the interarrival time between successive 
arrivals, $C_{I B P}^{2}$ are as follows (see [7]):

$$
\begin{aligned}
E\{t\} & =\frac{2-p-q}{\alpha(1-q)} \\
C_{I B P}^{2} & =\frac{\operatorname{Var}(t)}{E\{t\}^{2}} \\
& =1+\alpha\left[\frac{(1-p)(p+q)}{(2-p-q)^{2}}-1\right] .
\end{aligned}
$$

The average arrival rate, i.e. the probability that any slot contains a cell, $\rho_{I B P}$ is given by

$$
\rho_{I B P}=\frac{\alpha(1-q)}{2-p-q}
$$

By varying $p$ and $q$, we can increase the traffic and at the same time change the burstiness of the process.

\section{The Departure Process of an IBP/Geo/1/K Queue}

Let us consider a discrete-time single server queue. Let $\mathrm{K}$ be the maximum capacity of the queue. The service time is defined over a slotted time axis. For presentation purposes, a slot will be referred to as a service slot. A service always starts at the beginning of a service slot and the service time is assumed to be a geometric number of service slots with parameter $\sigma$. The arrival process is also defined over a slotted time axis with the same slot size, and it is assumed to be an IBP with parameters $p_{A}, q_{A}$, and $\alpha_{A}$. The boundaries of the slots of the arrival process is assumed to be in-between the boundaries of the service slots (as shown in Figure 2). An arriving cell to an empty queue cannot start its service until the beginning of the next service slot, even though the server is free at the time instant of its arrival. A departure is assumed to take place just before the end of service slot. Finally, as it will be seen below we examine this queue at the boundary of each service slot.

In order to analyze the departure process of an IBP/Geo/1/K, we first need to obtain its queue-length distribution. This is done numerically. That is, we first generate all possible 


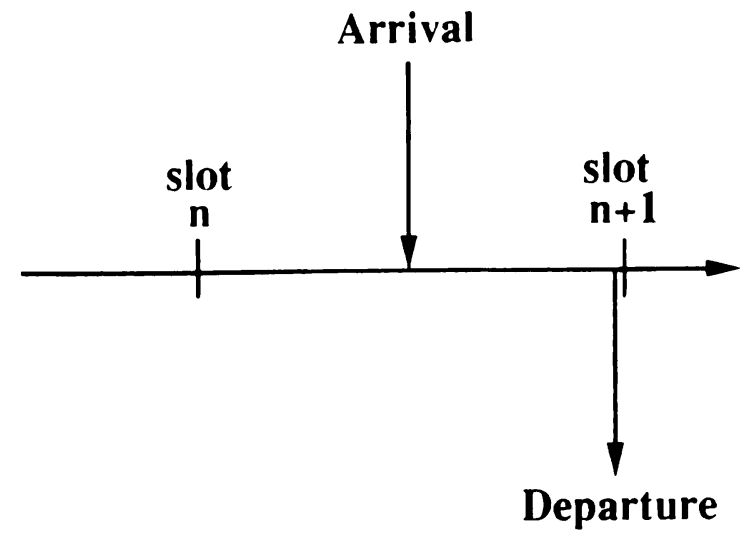

Figure 2: The arrival and the departure time instants

states for the queue length at the end of every service slot, and subsequently we generate the rate matrix $\mathbf{Q}$. The stationary probability vector $\mathbf{x}$ is then obtained by solving the linear equations $\times Q=0$. We define the state of the queue by the variables $(s, n)$. Variable $s$ represents the state of the arrival process at the end of a service slot and it takes the values: 0 if the arrival process is in the idle state, 1 if the arrival process is in the active state. Variable $n$ indicates the number of cells in the system at the end of a service slot. We have $n=0,1, . ., \mathrm{K}$, where $\mathrm{K}$ is the capacity of the system including the cell in service. Using the stationary probability vector $\mathbf{x}$, that can be obtained numerically as described above, we compute the generating function of the probability distribution of the interdeparture time of the IBP $/ \mathrm{Geo} / 1 / \mathrm{K}$ queue as follows.

Let $I$ be a random variable representing the time the server is idle (i.e. the system is idle). This is the time elapsing from the moment a departure occurs to the end of service slot during which an arrival occurs. Also, let $\mathbf{S}$ be a random variable representing the service time, and let $\mathbf{D}$ be a random variable representing the interdeparture time. These random variables are discrete-time and they take values which are integer multiples of a service slot. Let us consider two consecutive departure instants corresponding to the two departures of the $(m-1)$ st and $m$ th customer. The interdeparture interval $\mathbf{D}$ is equal to the sum of a server idle period plus service time of the $m$ th customer if the $(m-1)$ st departure leaves an 


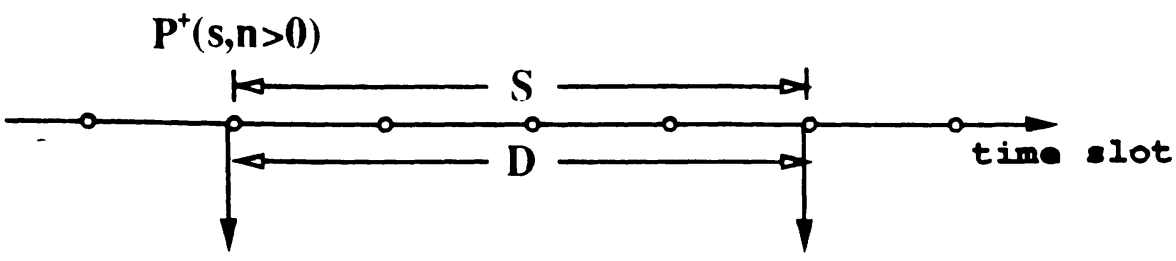

m-1 st Departure

m-th Departure

case 2

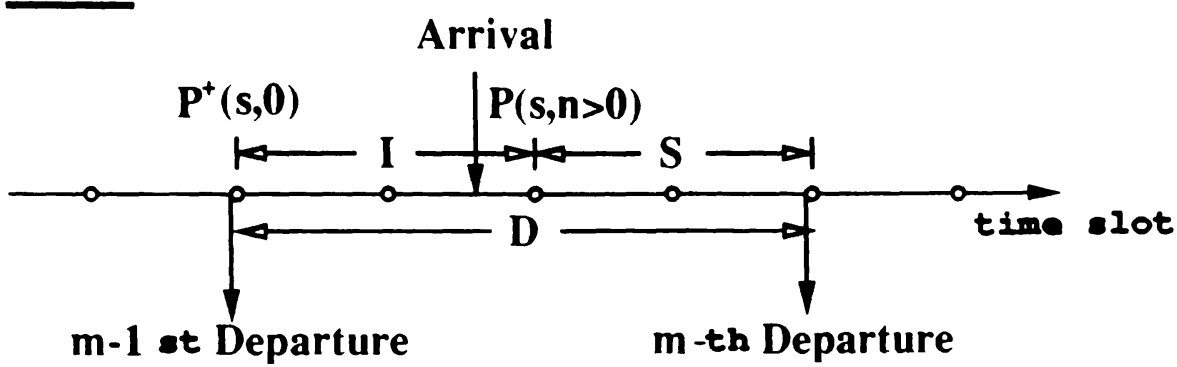

Figure 3: The interdeparture time

empty system, or it is equal to a service time if the system is not empty after the $(m-1)$ st departure. These two cases are shown in Figure 3. I can be expressed as follows:

$$
\mathbf{I}= \begin{cases}0 & 1-P^{+}(0,0)-P^{+}(1,0) \\ I_{0} & P^{+}(0,0) \\ I_{1} & P^{+}(1,0)\end{cases}
$$

where $I_{0}, I_{1}$ is a random variable indicating the time elapsing from the moment a departure occurs leaving the system in state $(0,0)$ respectively $(1,0)$ to the end of the service slot during where an arrival occurs. $P^{+}(s, n)$ is the probability that immediately after a departure the system is in the state $(s, n) . I_{0}, I_{1}$, and $P^{+}(s, n)$ can be obtained as follows:

$$
\begin{aligned}
& I_{0}=\left\{\begin{array}{cl}
1 & \left(1-q_{A}\right) \alpha_{A} \\
1+I_{0} & q_{A} \\
1+I_{1} & \left(1-q_{A}\right)\left(1-\alpha_{A}\right)
\end{array}\right. \\
& I_{1}=\left\{\begin{array}{cl}
1 & p_{A} \alpha_{A} \\
1+I_{0} & 1-p_{A} \\
1+I_{1} & p_{A}\left(1-\alpha_{A}\right)
\end{array}\right.
\end{aligned}
$$




$$
\begin{aligned}
P^{+}(s, n) & =\operatorname{Pr}\{\text { The system is in state }(\mathrm{s}, \mathrm{n}) \mid \text { a departure has occurred }\} \\
& =\frac{\operatorname{Pr}\{\text { The system is in }(\mathrm{s}, \mathrm{n}) \text { and a departure has occurred }\}}{\operatorname{Pr}\{\text { A departure occurs }\}} \\
P^{+}(0,0) & =\frac{(1-\sigma)\left[q_{A} P(0,1)+\left(1-p_{A}\right) P(1,1)\right]}{(1-\sigma)[1-P(0,0)-P(1,0)]} \\
& =\frac{q_{A} P(0,1)+\left(1-p_{A}\right) P(1,1)}{1-P(0,0)-P(1,0)} \\
P^{+}(1,0) & =\frac{\left(1-q_{A}\right)\left(1-\alpha_{A}\right) P(0,1)+p_{A}\left(1-\alpha_{A}\right) P(1,1)}{1-P(0,0)-P(1,0)}
\end{aligned}
$$

By taking the z-transform of the equation (5) and (6) we can get:

$$
\begin{aligned}
& I_{0}(z)=E\left(z^{I_{0}}\right)=\frac{\alpha_{A}\left(1-q_{A}\right) z}{\left(1-\alpha_{A}\right)\left(p_{A}+q_{A}-1\right) z^{2}-\left[q_{A}+p_{A}\left(1-\alpha_{A}\right)\right] z+1} \\
& I_{1}(z)=E\left(z^{I_{1}}\right)=\frac{\alpha_{A}\left(1-p_{A}-q_{A}\right) z^{2}+\alpha_{A} p_{A} z}{\left(1-\alpha_{A}\right)\left(p_{A}+q_{A}-1\right) z^{2}-\left[q_{A}+p_{A}\left(1-\alpha_{A}\right)\right] z+1},
\end{aligned}
$$

where $I_{0}(z)$ and $I_{1}(z)$ are the z-transforms of $I_{0}$ and $I_{1}$, respectively. Using (4), (7), (8), $(9)$ and (10) we can obtain the following expression for $I(z)$, the generating function of $I$ :

$$
I(z)=1-P^{+}(0,0)-P^{+}(1,0)+P^{+}(0,0) I_{0}(z)+P^{+}(1,0) I_{1}(z)
$$

We define $\mathrm{D}(\mathrm{z})$ as the generating function of the probability distribution of the interdeparture time. We have $\mathrm{D}=\mathrm{S}+\mathrm{I}$. Since $\mathrm{S}$ and $\mathrm{I}$ are independent, $D(z)=E\left\{z^{D}\right\}=S(z) I(z)$, where $S(z)$ is the generating functions of $\mathrm{S}$, and it is equal to $S(z)=\frac{(1-\sigma) z}{1-\sigma z}$. Thus, we have

$$
D(z)=\frac{a_{3} z^{3}+a_{2} z^{2}+a_{1} z}{b_{3} z^{3}+b_{2} z^{2}+b_{1} z+1}
$$

where

$$
a_{3}=(1-\sigma)\left(p_{A}+q_{A}-1\right)\left\{\left(1-\alpha_{A}\right)\left[1-P^{+}(0,0)\right]-P^{+}(1,0)\right\}
$$




$$
\begin{aligned}
& a_{2}=(1-\sigma)\left\{\left(p_{A}+q_{A}\right)\left[\left(1-\alpha_{A}\right) P^{+}(0,0)+P^{+}(1,0)-1\right]+\alpha_{A}\left[P^{+}(0,0)+p_{A}\right]\right\} \\
& a_{1}=(1-\sigma)\left[1-P^{+}(0,0)-P^{+}(1,0)\right] \\
& b_{3}=-\sigma\left(1-\alpha_{A}\right)\left(p_{A}+q_{A}-1\right) \\
& b_{2}=\left(1-\alpha_{A}\right)\left(p_{A}+q_{A}-1\right)+\sigma\left[q_{A}+p_{A}\left(1-\alpha_{A}\right)\right] \\
& b_{1}=-\left[\sigma+q_{A}+p_{A}\left(1-\alpha_{A}\right)\right]
\end{aligned}
$$

The moments of the time between successive departures can be obtained by differentiating $D(z)$ given by (11). In particular, the mean interdeparture time $E\{D\}$ and the squared coefficient of variation of the interdeparture time $C^{2}$, are as follows:

$$
\begin{aligned}
E\{D\} & =D^{\prime}(1) \\
C^{2} & =\frac{\operatorname{Var}(D)}{E\{D\}^{2}} \\
& =\frac{D^{\prime \prime}(1)+D^{\prime}(1)-\left[D^{\prime}(1)\right]^{2}}{\left[D^{\prime}(1)\right]^{2}}
\end{aligned}
$$

where

$$
\begin{aligned}
D^{\prime}(1)= & \left.\frac{1}{1-\alpha_{A}}+P^{+}(0,0)\left[\frac{\left(1-\alpha_{A}\right)\left(1-p_{A}-q_{A}\right)+1}{\alpha_{A}\left(1-q_{A}\right)}\right]+P^{+}(1,0)\right)\left[\frac{2-p_{A}-q_{A}}{\alpha_{A}\left(1-q_{A}\right)}\right] \\
D^{\prime \prime}(1)= & P^{+}(0,0)\left[\frac{2\left(1-\alpha_{A}\right)\left(p_{A}+q_{A}-1\right)\left[\alpha_{A}\left(1-q_{A}\right)+p_{A}\left(1-\alpha_{A}\right)+q_{A}-4\right]}{\left[\alpha_{A}\left(1-q_{A}\right)\right]^{2}}\right] \\
& +P^{+}(1, n)\left[\frac{2\left(1-p_{A}-q_{A}\right)}{\alpha_{A}\left(1-q_{A}\right)}-\frac{2\left(2-p_{A}-q_{A}\right)\left[\left(1-\alpha_{A}\right)\left(p_{A}+2 q_{A}-2\right)-q_{A}\right]}{\left[\alpha_{A}\left(1-q_{A}\right)\right]^{2}}\right] \\
& +\frac{2}{1-\sigma}\left[\frac{P^{+}(0,0)\left(1-\alpha_{A}\right)\left(1-p_{A}-q_{A}\right)+1}{\alpha_{A}\left(1-q_{A}\right)}+\frac{P^{+}(1,0)\left(2-p_{A}-q_{A}\right)}{\alpha_{A}\left(1-q_{A}\right)}\right] \\
& +P^{+}(0,0)\left[\frac{2\left[q_{A}+p_{A}\left(1-\alpha_{A}\right)\right]}{\left[\alpha_{A}\left(1-q_{A}\right)\right]^{2}}\right]+\frac{2 \sigma}{(1-\sigma)^{2}} .
\end{aligned}
$$

The link utilization, $\rho$, i.e., the probability that any slot contains a cell is:

$$
\rho=\frac{1}{D^{\prime}(1)}
$$


and the third moment of the interdeparture time, $E\left\{D^{3}\right\}$, is:

$$
\begin{aligned}
E\left\{D^{3}\right\} & =D^{\prime \prime \prime}(1)+3 D^{\prime \prime}(1)+D^{\prime}(1) \\
& =D^{\prime \prime \prime}(1)+\frac{1}{\rho^{2}}\left[3\left(C^{2}+1\right)-2 \rho\right]
\end{aligned}
$$

where $\left.D^{\prime \prime \prime}(1)=\frac{d^{3} D(z)}{d z^{3}}\right]_{z=1}$.

The probability distribution of the interdeparture time can be obtained by inverting the generating function, $D(z)$. This is done as follows (see Kobayashi [4]). Let $p_{i}$ be the probability that the interdeparture time is equal to $i$ slots. Then, we have

$$
D(z)=\frac{\sum_{i=0}^{3} a_{i} z^{i}}{\sum_{i=0}^{3} b_{i} z^{i}}=\sum_{i=0}^{\infty} p_{i} z^{i}
$$

where $b_{0}=1$. Multiplying both sides by the denominator and then equating the coefficients of $z^{i}$ on both sides, we obtain the following set of linear difference equations:

$$
\sum_{j=0}^{\min \{3, i\}} p_{i-j} b_{j}=\left\{\begin{array}{ll}
a_{i} & i=0,1,2,3 \\
0 & i>3
\end{array} .\right.
$$

We can then solve for $p_{i}, i=0,1, \cdots$, recursively as follows:

$$
p_{i}=\frac{1}{b_{0}}\left[a_{i}-\sum_{j=1}^{\min \{3, i\}} b_{j} p_{i-j}\right], \quad i=0,1, \cdots
$$

where $a_{i}=0$ for $i>3$.

\section{Characterizing the Departure Process by an IBP}

As mentioned in section 2, an IBP can be expressed by the three parameters, $p, q$, and $\alpha$. Therefore, in order to characterize the departure process by an IBP, we have to estimate $p$, $q$, and $\alpha$. We first note that from the generating function, $D(z)$, obtained in the previous 
section, we can obtain the first three moments of the distribution of the interdeparture time. Matching these three moments against the three moments of the IBP, we can obtain three equations from which the three parameters can be computed. This is how the parameters of a two-phased Coxian distribution are commonly obtained. However, in the discretetime case, this is not a simple task since the third moment of an IBP is a fairly complex expression (see equation (22)). Also, it cannot be guaranteed that there is a feasible solution for the parameters of the IBP. In this section, we examine several models for characterizing approximately the departure process by an IBP.

\subsection{Model 1}

Let us consider the set of all states of the queue from which it is possible to have an attempted departure. If the queue is in one of these states, then the departure process is assumed to be in its active state. The set of all these states will be referred to by the symbol $A$. Probability $p$ can then be obtained as the probability that the queue will be in an active state in the next slot, given that it is currently in an active state. Probability $q$ can be obtained similarly by considering the set of states of the queue from which it is not possible to have a departure. If the queue is in one of these states, then the departure process is assumed to be in its idle state. We shall refer to these states as the idle states and their set will be referred to by the symbol $I$. We define the idle states to be the state in which the queue is empty and arrival process is in the idle state, i.e. $I=\{(0,0)\}$. Alternatively, we can define $I=\{(0,0),(1,0)\}$, i.e. we can also include the state where the queue is empty and the arrival process is in the active state. Empirically, we found that the latter definition does not give as good result as the former one. Consequently, we will set $I=\{(0,0)\}$.

Using the steady-state probability, $P(s, n)$ and the transition probabilities from state $(s, n)$ to state $(\bar{s}, \bar{n}), t[(s, n) \rightarrow(\bar{s}, \bar{n})]$, the probabilities $p$ and $q$ can be calculated as follows (see 
Morris and Perros [5]).

$$
p=\frac{\sum_{(s, n) \in A} P(s, n)\left[\sum_{(s, n) \in A} t[(s, n) \rightarrow(\bar{s}, \bar{n})]\right]}{\sum_{(s, n) \in A} P(s, n)},
$$

and

$$
q=\frac{\sum_{(s, n) \in I} P(s, n)\left[\sum_{(s, n) \in I} t[(s, n) \rightarrow(\bar{s}, \bar{n})]\right]}{\sum_{(s, n) \in I} P(s, n)} .
$$

Using the above approach, we can estimate $p$ or $q$ or both. In model 1 , we estimate $p$ (or $q$ ) and the other two unknowns $q$ (or $p$ ) and $\alpha$ are obtained from $\rho$ and $C^{2}$ of the departure process. In particular, we have the following two cases:

Model 1a : $p$ is estimated using (16). $q$ and $\alpha$ are then estimated as follows. We first calculate $\rho$ and $C^{2}$ of the departure process using (14) and (15) respectively. Then, we set $\rho_{I B P}=\rho$ and $C_{I B P}^{2}=C^{2}$ in (3) and (2) and solve for $q$ and $\alpha$. We have:

$$
\left\{\begin{array}{l}
2 p \alpha^{2}+\left[(p-1)\left(C^{2}-1\right)-(p+3) \rho\right] \alpha+2 \rho^{2}=0 \\
q=\frac{\alpha-2 \rho+p \rho}{\alpha-\rho}
\end{array}\right.
$$

Model 1b : $q$ is estimated using (17). $p$ and $\alpha$ are estimated as in model 1 a from

(2) and (3). We have:

$$
\left\{\begin{array}{l}
2(1-q) \alpha^{2}+\left[C^{2}-1-3 \rho-\left(C^{2}-1-\rho\right) q\right] \alpha+2 \rho^{2}=0 \\
p=2-q-\frac{\alpha(1-q)}{\rho}
\end{array}\right.
$$

We note that in either case it is possible to have two roots for $\alpha$ which means that in model 1a (model 1b) we may have two different values for $q(p)$.

Models $1 \mathrm{a}$ and $1 \mathrm{~b}$ can not be guaranteed to give a feasible solution for the two parameters obtained from $\rho$ and $C^{2}$ of the departure process. For a given $\rho$ and $C^{2}$, the solutions for 
$q$ (or $p$ ) and $\alpha$ may violate the basic conditions, $0<p<1,0<q<1$, and $0<\alpha \leq 1$. (Expression (16) and (17) always satisfies the basic condition.)

\subsection{Model 2}

Unlike model 1, we obtain both parameters, $p$ and $q$ using (16) and (17). $\alpha$ is calculated by matching either $\rho$ with $\rho_{I B P}$ in (3) or $C^{2}$ with $C_{I B P}^{2}$ in (2). We have the following two cases:

Model 2a (matching $\rho)$ :

$$
\alpha=\frac{\rho(2-p-q)}{1-q}
$$

Model 2b (matching $C^{2}$ ):

$$
\alpha=\frac{\left(C^{2}-1\right)(2-p-q)^{2}}{(1-p)(p+q)-(2-p-q)^{2}}
$$

If we use equation (18) to obtain $\alpha$, then the solution for $\alpha$ is always feasible. However, from equation (19) we do not always obtain a feasible solution for $\alpha$, i.e. $\alpha$ is not always within the range $0<\alpha \leq 1$.

\subsection{Model 3}

Unlike models 1 and 2, we do not estimate $p$ or $q$ from equations (16) and (17). Given $\alpha$, where $0<\alpha \leq 1$, we can obtain $p$ and $q$ by matching $\rho$ and $C^{2}$ with $\rho_{I B P}$ and $C_{I B P}^{2}$ in and (2) respectively. From equations (2) and (3) we have

$$
p=\frac{\left(C^{2}-1\right) \alpha+3 \alpha \rho-2 \rho^{2}}{\left(C^{2}-1\right) \alpha-\alpha \rho+2 \alpha^{2}}
$$

and

$$
\begin{aligned}
q & =\frac{\alpha-2 \rho+p \rho}{\alpha-\rho} \\
& =\frac{\left(C^{2}-1\right) \alpha-3 \alpha \rho+2 \alpha^{2}+2 \rho^{2}}{\left(C^{2}-1\right) \alpha-\alpha \rho+2 \alpha^{2}}
\end{aligned}
$$


$p$ and $q$ are feasible, i.e. $0<p<1$ and $0<q<1$ if the following conditions hold (for a proof see Appendix):

$$
\begin{aligned}
& \rho<\alpha \leq 1 \\
& \left(C^{2}-1\right) \alpha+3 \alpha \rho-2 \rho^{2}>0 \\
& \left(C^{2}-1\right) \alpha-3 \alpha \rho+2 \alpha^{2}+2 \rho^{2}>0
\end{aligned}
$$

condition(1)

condition(2)

condition(3)

$\alpha$ is obtained as follows.

\section{Model 3a:}

Among all feasible solutions for $\alpha$ which satisfy the above conditions, we select $\alpha$ so that the resulting IBP has the smallest error $\epsilon$. This error is calculated as follows. Let $P_{\text {exact }}\{D=i\}$ be the exact probability that the interdeparture time is equal to $i \operatorname{slot}(\mathrm{s})$. Let $P_{\text {est }}\{D=i\}$ be the estimated probability that the interdeparture time is equal to $i \operatorname{slot}(\mathrm{s})$. Then, we have

$$
\epsilon=\sum_{i=1}^{n}\left|P_{\text {exact }}\{D=i\}-P_{\text {est }}\{D=i\}\right|
$$

where $n$ is the number of distribution points to be compared. Model 3a is summarized as follows:

step $0:$ Set $\alpha=\rho, \delta=1.0 E-6$, and $\epsilon^{(0)}=1.0 E+30$.

step 1: Set $\alpha=\alpha+\delta$. If $\alpha>1$, Stop.

step 2: Check for condition(2) and (3). If not satisfied, go to step 1. Else calculate $p$ and $q$ using equations (20) and (21).

step 3 : Compute the distribution of the interdeparture time, and calculate $\epsilon^{(1)}=\epsilon$. If $\epsilon^{(0)}>{ }^{(1)}, \epsilon^{(0)}=\epsilon^{(1)}$. Go to step 1

\section{Model 3b:}

In order to speed up the above algorithm, we introduce the following modification. Instead of comparing the distribution of the interdeparture time, we compare the third moment of the interdeparture time with the estimated one. The expression for the third moment of an IBP is:

$$
E\left\{D^{3}\right\}=6\left[\frac{2(1-\alpha)}{(1-q) \rho^{2}}+\frac{q}{(1-q)^{2} \rho}-\frac{2(1-\alpha)}{\alpha(1-q) \rho}-\frac{q}{\alpha(1-q)^{2}}+\frac{(1-\alpha)^{2}}{\rho^{3}}\right]
$$




$$
+\frac{3 C^{2}+3-2 \rho}{\rho^{2}}
$$

We obtain a value for $\alpha$ for which the set $(p, q, \alpha)$ is such that the difference between the value of the third moment of the interdeparture time from equation (15) and the value from equation (22) by substituting the set of $(p, q, \alpha)$ is minimum.

A further speed-up can be obtained by determining $\alpha$ intuitively (for instance, we can set $\alpha=1-\sigma)$ and then we obtain $\mathrm{p}$ and $\mathrm{q}$ in terms of $\rho, C^{2}$ and $\alpha$ using equations (20) and (21). This method is much faster than model $3 a$ or $3 b$, but it is difficult to determine the value of $\alpha$ so that we can get a feasible solution for $p$ and $q$ and a good fit. The value of $\alpha=1-\sigma$ does not always give good results.

\subsection{Validation}

We tested 9 different departure processes. Each process corresponds to a combination of small, medium and large $\rho$ and $C^{2}$. The results are given in tables 1 to 9 . Each table gives the values for $\rho, C^{2}$, and the third moment, $E\left\{D^{3}\right\}$, obtained using models $1 \mathrm{a}, 1 \mathrm{~b}, 2 \mathrm{a}, 2 \mathrm{~b}$, 3a, and 3b. The exact values for $\rho$, and $C^{2}$, and $E\left\{D^{3}\right\}$ are also given. For each model we give the error computed using the expression

$$
\text { Error }=\sum_{i=1}^{50}\left|P_{\text {exact }}\{D=i\}-P_{\text {eat }}\{D=i\}\right|
$$

The parameters of the arrival process $\left(p_{A}, q_{A}, \alpha_{A}\right), \sigma$, and buffer capacity $\mathrm{K}$ of the queue under study are given in the legend.

From tables 1-9, we see that model $1 a, 1 b, 2 a, 3 a$, and $3 b$ give good results. Model $3 a$ gives the best results since it selects a set of $(p, q, \alpha)$ for which the difference between the exact and estimated distribution is minimal. However, it is time-consuming, especially when $\rho$ is small, since a large number of feasible solutions have to be tested in order to find the minimum. The accuracy of model $3 a$ depends on the number of points along the distribution that are compared. We also note that the estimated $C^{2}$ using model $2 \mathrm{a}$ is slightly different 
from the exact value. Finally, in some cases, the accuracy of the estimated distribution of the interdeparture time and the estimated $\rho$ using model $2 \mathrm{~b}$ is not as good as in the other models.

Experimentation has shown that model la gives good results if the estimated parameters of the IBP are all feasible. Hence, the following strategy can be used for fitting an IBP. Use model $1 \mathrm{a}$ if the parameters of the IBP are all feasible. If the solution is not feasible, then use model $2 \mathrm{a}$.

The goodness of fit depends on the characteristics of the departure process. Generally speaking, for a departure process with large $C^{2}$ and $\rho$, we can have a comparatively good fit. When $\rho$ is small we can still obtain good results if $C^{2}$ is large. For the departure process with very high $\rho$, we can also obtain good results even when the $C^{2}$ of the departure process is very low. 


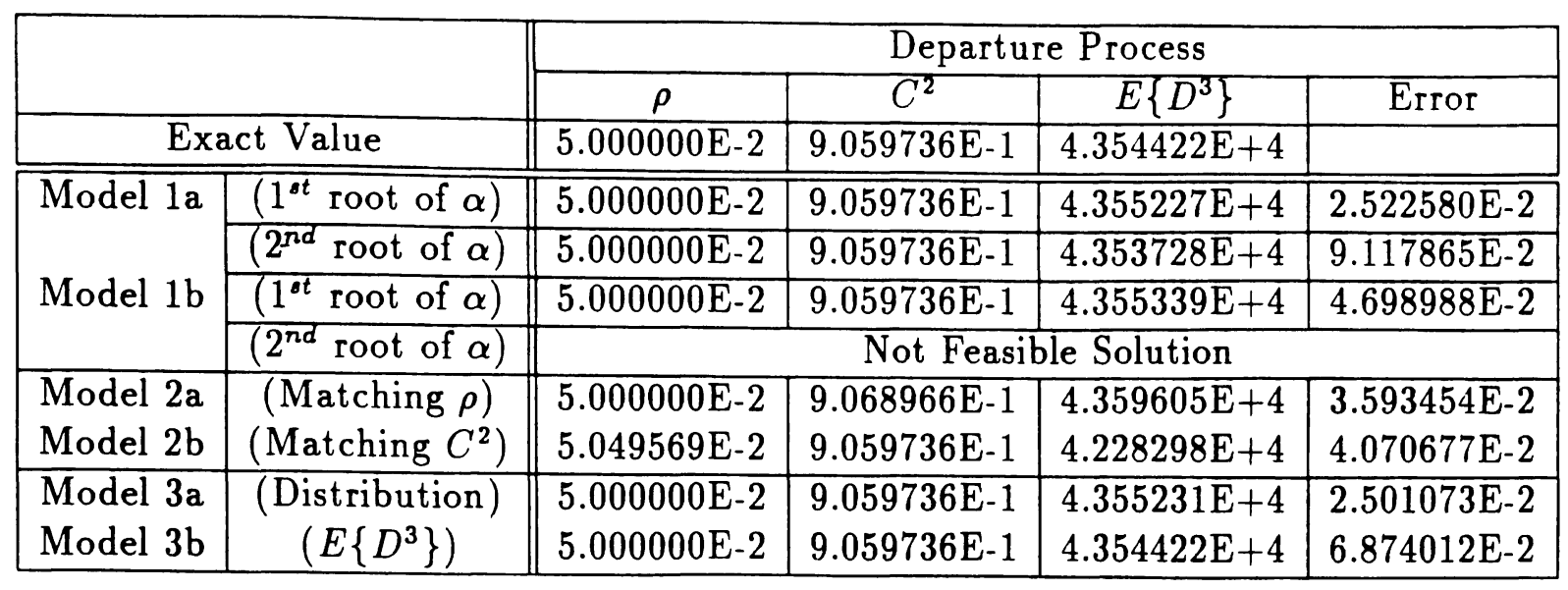

Table 1: A.rrival Process $\left(p_{A}=0.1, q_{A}=0.1, \alpha_{A}=0.1\right), \sigma=0.1, \mathrm{~K}=10$

\begin{tabular}{|c|c||c|c|c|c|}
\hline \multicolumn{2}{|c||}{} & \multicolumn{4}{c|}{ Departure Process } \\
\cline { 3 - 6 } & $\rho$ & $C^{2}$ & $E\left\{D^{3}\right\}$ & Error \\
\hline \multicolumn{2}{|c||}{ Exact Value } & $5.791028 \mathrm{E}-2$ & $1.003341 \mathrm{E}+1$ & $1.060041 \mathrm{E}+6$ & \\
\hline \hline \multirow{2}{*}{ Model 1a } & $\left(1^{\text {st }}\right.$ root of $\left.\alpha\right)$ & $5.791028 \mathrm{E}-2$ & $1.003341 \mathrm{E}+1$ & $1.060041 \mathrm{E}+6$ & $3.887366 \mathrm{E}-2$ \\
\cline { 2 - 6 } & $\left(2^{\text {nd }}\right.$ root of $\left.\alpha\right)$ & \multicolumn{4}{c|}{ Not Feasible Solution } \\
\cline { 2 - 6 } Model 1b & $\left(1^{\text {st }}\right.$ root of $\left.\alpha\right)$ & $5.791028 \mathrm{E}-2$ & $1.003341 \mathrm{E}+1$ & $1.073717 \mathrm{E}+6$ & $5.791028 \mathrm{E}-2$ \\
\cline { 2 - 6 } & $\left(2^{\text {nd }}\right.$ root of $\left.\alpha\right)$ & $5.791028 \mathrm{E}-2$ & $1.003341 \mathrm{E}+1$ & $9.897953 \mathrm{E}+5$ & $9.457852 \mathrm{E}-1$ \\
\hline Model 2a & $($ Matching $\rho)$ & $5.791028 \mathrm{e}-02$ & $1.014616 \mathrm{E}+1$ & $1.081033 \mathrm{E}+6$ & $4.328753 \mathrm{E}-2$ \\
Model 2b & $\left(\right.$ Matching $\left.C^{2}\right)$ & $5.719640 \mathrm{E}-2$ & $1.003341 \mathrm{E}+1$ & $1.098882 \mathrm{E}+6$ & $3.805224 \mathrm{E}-2$ \\
\hline Model 3a & $($ Distribution $)$ & $5.791028 \mathrm{E}-2$ & $1.003341 \mathrm{E}+1$ & $1.062264 \mathrm{E}+6$ & $2.510501 \mathrm{E}-2$ \\
Model 3b & $\left(E\left\{D^{3}\right\}\right)$ & $5.791028 \mathrm{E}-2$ & $1.003341 \mathrm{E}+1$ & $1.061938 \mathrm{E}+6$ & $3.151992 \mathrm{E}-2$ \\
\hline
\end{tabular}

Table 2: Arrival Process $\left(p_{A}=0.931, q_{A}=0.99, \alpha_{A}=0.458\right), \sigma=0.5, \mathrm{~K}=10$

\begin{tabular}{|c|c|c|c|c|c|}
\hline & & \multicolumn{4}{|c|}{ Departure Process } \\
\hline & & $\rho$ & $C^{2}$ & $E\left\{\bar{D}^{3}\right\}$ & Error \\
\hline \multicolumn{2}{|c|}{ Exact Value } & $5.152882 \mathrm{E}-2$ & $4.547770 \mathrm{E}+2$ & $2.579378 \mathrm{E}+9$ & \\
\hline \multirow[t]{2}{*}{$\overline{\text { Model 1a }}$} & $\left(1^{\text {`t }}\right.$ root of $\left.\alpha\right)$ & $5.152882 \mathrm{E}-2$ & $\overline{4.547770 \mathrm{E}+2}$ & $2.579377 \mathrm{E}+9$ & $\overline{7.258830 \mathrm{E}-4}$ \\
\hline & $\left(2^{\text {nd }}\right.$ root of $\left.\alpha\right)$ & \multicolumn{4}{|c|}{ Not Feasible Solution } \\
\hline \multirow[t]{2}{*}{ Model 1b } & $\left(1^{\text {st }}\right.$ root of $\left.\alpha\right)$ & $5.152882 \mathrm{E}-2$ & $4.547770 \bar{E}+2$ & $2.579381 \mathrm{E}+9$ & $7.203384 \mathrm{E}-4$ \\
\hline & $\left(2^{\text {nd }}\right.$ root of $\left.\alpha\right)$ & \multicolumn{4}{|c|}{ Not Feasible Solution } \\
\hline Model 2a & (Matching $\rho$ ) & $5.152882 \mathrm{E}-2$ & $4.547778 \mathrm{E}+2$ & $2.579386 \mathrm{E}+9$ & $7.265276 \mathrm{E}-4$ \\
\hline Model 2b & (Matching $C^{2}$ ) & $5.152872 \mathrm{E}-2$ & $4.547770 \mathrm{E}+2$ & $2.579391 \mathrm{E}+9$ & $7.257103 \mathrm{E}-4$ \\
\hline Model 3a & (Distribution) & $5.152882 \mathrm{E}-2$ & $4.547770 \mathrm{E}+2$ & $2.579598 \mathrm{E}+9$ & $5.619398 \mathrm{E}-4$ \\
\hline Model 3b & $\left(E\left\{D^{3}\right\}\right)$ & $5.152882 \mathrm{E}-2$ & $4.547770 \mathrm{E}+2$ & $2.579378 \mathrm{E}+9$ & $7.139101 \mathrm{E}-4$ \\
\hline
\end{tabular}

Table 3: Arrival Process $\left(p_{A}=0.9985, q_{A}=0.9998, \alpha_{A}=0.438\right), \sigma=0.3, \mathrm{~K}=10$ 


\begin{tabular}{|c|c||c|c|c|c|}
\hline \multicolumn{2}{|c||}{} & \multicolumn{4}{c|}{ Departure Process } \\
\cline { 3 - 6 } \multicolumn{2}{|c||}{ Exact Value } & $\rho$ & $C^{2}$ & $E\left\{D^{3}\right\}$ & Error \\
\hline \multicolumn{2}{|c|}{} & $4.536092 \mathrm{E}-1$ & $5.125532 \mathrm{E}-1$ & $3.486905 \mathrm{E}+1$ & \\
\hline \hline \multirow{3}{*}{ Model 1a } & $\left(1^{\text {st }}\right.$ root of $\left.\alpha\right)$ & \multicolumn{4}{c|}{ Not Feasible Solution } \\
\cline { 2 - 6 } & $\left(2^{\text {nd }}\right.$ root of $\left.\alpha\right)$ & \multicolumn{4}{c|}{ Not Feasible Solution } \\
\cline { 2 - 6 } & $\left(1^{\text {ot }}\right.$ root of $\left.\alpha\right)$ & $4.536092 \mathrm{E}-1$ & $5.125532 \mathrm{E}-1$ & $3.520111 \mathrm{E}+1$ & $2.368045 \mathrm{E}-2$ \\
\cline { 2 - 6 } & $\left(2^{\text {nd }}\right.$ root of $\left.\alpha\right)$ & \multicolumn{4}{|c|}{ Not Feasible Solution } \\
\hline Model 2a & $($ Matching $\rho)$ & $4.536092 \mathrm{E}-1$ & $5.798944 \mathrm{E}-1$ & $3.970193 \mathrm{E}+1$ & $5.798405 \mathrm{E}-2$ \\
Model 2b & $\left(\right.$ Matching $\left.C^{2}\right)$ & $5.263209 \mathrm{E}-1$ & $5.125532 \mathrm{E}-1$ & $2.318192 \mathrm{E}+1$ & $1.942099 \mathrm{E}-1$ \\
\hline Model 3a & $($ Distribution $)$ & $4.536092 \mathrm{E}-1$ & $5.125532 \mathrm{E}-1$ & $3.518739 \mathrm{E}+1$ & $2.160386 \mathrm{E}-2$ \\
Model 3b & $\left(E\left\{D^{3}\right\}\right)$ & $4.536092 \mathrm{E}-1$ & $5.125532 \mathrm{E}-1$ & $3.518739 \mathrm{E}+1$ & $2.143936 \mathrm{E}-2$ \\
\hline
\end{tabular}

Table 4: Arrival Process $\left(p_{A}=0.38, q_{A}=0.35, \alpha_{A}=0.9\right), \sigma=0.5, \mathrm{~K}=10$

\begin{tabular}{|c|c|c|c|c|c|}
\hline & \multicolumn{4}{|c|}{ Departure Process } \\
\hline & & $\rho$ & $C^{2}$ & $E\left\{D^{3}\right\}$ & Error \\
\hline \multicolumn{2}{|c|}{ Exact Value } & $4.442376 \mathrm{E}-1$ & $1.154362 \mathrm{E}+1$ & $8.887376 \mathrm{E}+3$ & \\
\hline \multirow{4}{*}{$\begin{array}{l}\text { Model 1a } \\
\text { Model 1b }\end{array}$} & $\left(1^{\text {st }}\right.$ root of $\left.\alpha\right)$ & $4.442376 \mathrm{E}-1$ & $1.154362 \mathrm{E}+1$ & $8.843527 \bar{E}+3$ & $2.988950 \mathrm{E}-3$ \\
\hline & $\left(2^{\text {nd }}\right.$ root of $\left.\alpha\right)$ & \multicolumn{4}{|c|}{ Not Feasible Solution } \\
\hline & $\left(1^{\text {st }}\right.$ root of $\left.\alpha\right)$ & $4.442376 \mathrm{E}-1$ & $1.154362 \mathrm{E}+1$ & $8.920011 \mathrm{E}+3$ & $1.432366 \mathrm{E}-3$ \\
\hline & $\left(2^{\text {nd }} \operatorname{root}\right.$ of $\left.\alpha\right)$ & \multicolumn{4}{|c|}{ Not Feasible Solution } \\
\hline Mo & $\overline{(\text { Matching } \rho)}$ & 4.442 & $1.172159 \mathrm{E}+1$ & $9.062557 \mathrm{E}+3$ & $5.744578 \mathrm{E}-3$ \\
\hline $2 b$ & $(\mathrm{Ma}$ & $4.368380 \mathrm{E}-1$ & $1.154362 \mathrm{E}+1$ & $9.230488 \mathrm{E}+3$ & $1.416369 \mathrm{E}-2$ \\
\hline lel 3a & (Distril & $4.442376 \mathrm{E}-1$ & $1.154362 \mathrm{E}+1$ & $8.901693 \mathrm{E}+3$ & $6.735641 \mathrm{E}-4$ \\
\hline Model 3b & $\left(E\left\{D^{3}\right\}\right)$ & $4.442376 \mathrm{E}-1$ & $1.154362 \mathrm{E}+1$ & $8.887359 E+3$ & $9.321133 \mathrm{E}-4$ \\
\hline
\end{tabular}

Table 5: Arrival Process $\left(p_{A}=0.99, q_{A}=0.98, \alpha_{A}=0.92\right), \sigma=0.4, \mathrm{~K}=10$

\begin{tabular}{|c|c||c|c|c|c|}
\hline \multicolumn{2}{|c||}{} & \multicolumn{4}{c|}{ Departure Process } \\
\cline { 3 - 6 } & $\rho$ & $C^{2}$ & $E\left\{D^{3}\right\}$ & Error \\
\hline \multicolumn{2}{|c||}{ Exact Value } & $4.343637 \mathrm{E}-1$ & $4.667238 \mathrm{E}+2$ & $7.821237 \mathrm{E}+6$ & \\
\hline \hline \multirow{3}{*}{ Model 1a } & $\left(1^{\text {ot }}\right.$ root of $\left.\alpha\right)$ & $4.343637 \mathrm{E}-1$ & $4.667238 \mathrm{E}+2$ & $7.821195 \mathrm{E}+6$ & $5.623969 \mathrm{E}-4$ \\
\cline { 2 - 6 } & $\left(2^{\text {nd }}\right.$ root of $\left.\alpha\right)$ & \multicolumn{4}{|c|}{ Not Feasible Solution } \\
\cline { 2 - 6 } & $\left(1^{\text {ot }}\right.$ root of $\left.\alpha\right)$ & $4.343637 \mathrm{E}-1$ & $4.667238 \mathrm{E}+2$ & $7.821347 \mathrm{E}+6$ & $5.344818 \mathrm{E}-4$ \\
\cline { 2 - 6 } & $\left(2^{\text {nd }}\right.$ root of $\left.\alpha\right)$ & \multicolumn{5}{c|}{ Not Feasible Solution } \\
\hline Model 2a & (Matching $\rho)$ & $4.343637 \mathrm{E}-1$ & $4.667373 \mathrm{E}+2$ & $7.821572 \mathrm{E}+6$ & $5.760301 \mathrm{E}-4$ \\
Model 2b & $\left(\right.$ Matching $\left.C^{2}\right)$ & $4.343511 \mathrm{E}-1$ & $4.667238 \mathrm{E}+2$ & $7.821800 \mathrm{E}+6$ & $5.362369 \mathrm{E}-4$ \\
\hline Model 3a & (Distribution) & $4.343637 \mathrm{E}-1$ & $4.667238 \mathrm{E}+2$ & $7.822625 \mathrm{E}+6$ & $3.000837 \mathrm{E}-4$ \\
Model 3b & $\left(E\left\{D^{3}\right\}\right)$ & $4.343637 \mathrm{E}-1$ & $4.667238 \mathrm{E}+2$ & $7.821239 \mathrm{E}+6$ & $5.540679 \mathrm{E}-4$ \\
\hline
\end{tabular}

Table 6: Arrival Process $\left(p_{A}=0.999, q_{A}=0.99905, \alpha_{A}=0.9\right), \sigma=0.1, \mathrm{~K}=10$ 


\begin{tabular}{|c|c||c|c|c|c|}
\hline \multicolumn{2}{|c||}{} & \multicolumn{4}{c|}{ Departure Process } \\
\cline { 3 - 6 } \multicolumn{2}{|c||}{} & $\rho$ & $C^{2}$ & $E\left\{D^{3}\right\}$ & Error \\
\hline \multicolumn{2}{|c||}{ Exact Value } & $8.946945 \mathrm{E}-1$ & $1.051590 \mathrm{E}-1$ & $1.998816 \mathrm{E}+0$ & \\
\hline \hline \multirow{3}{*}{ Model 1a } & $\left(1^{\text {st }}\right.$ root of $\left.\alpha\right)$ & \multicolumn{4}{|c|}{ Not Feasible Solution } \\
\cline { 2 - 6 } & $\left(2^{\text {nd }}\right.$ root of $\left.\alpha\right)$ & \multicolumn{4}{|c|}{ Not Feasible Solution } \\
\cline { 2 - 6 } & $\left(1^{\text {st }}\right.$ root of $\left.\alpha\right)$ & \multicolumn{4}{|c|}{ Not Feasible Solution } \\
\cline { 2 - 6 } & $\left(2^{\text {nd }}\right.$ root of $\left.\alpha\right)$ & \multicolumn{4}{|c|}{ Not Feasible Solution } \\
\hline Model 2a & (Matching $\rho)$ & $8.946945 \mathrm{E}-1$ & $1.053550 \mathrm{E}-1$ & $2.000522 \mathrm{E}+0$ & $3.068693 \mathrm{E}-4$ \\
Model 2b & $\left(\right.$ Matching $\left.C^{2}\right)$ & $8.948905 \mathrm{E}-1$ & $1.051590 \mathrm{E}-1$ & $1.998057 \mathrm{E}+0$ & $6.164025 \mathrm{E}-4$ \\
\hline Model 3a & $($ Distribution $)$ & $8.946945 \mathrm{E}-1$ & $1.051590 \mathrm{E}-1$ & $1.998700 \mathrm{E}+0$ & $1.837207 \mathrm{E}-5$ \\
Model 3b & $\left(E\left\{D^{3}\right\}\right)$ & $8.946945 \mathrm{E}-1$ & $1.051590 \mathrm{E}-1$ & $1.998700 \mathrm{E}+0$ & $1.835226 \mathrm{E}-5$ \\
\hline
\end{tabular}

Table 7: Arrival Process $\left(p_{A}=0.9999, q_{A}=0.4999, \alpha_{A}=0.91\right), \sigma=0.1, \mathrm{~K}=10$

\begin{tabular}{|c|c||c|c|c|c|}
\hline \multicolumn{2}{|c||}{} & \multicolumn{4}{c|}{ Departure Process } \\
\cline { 3 - 6 } \multicolumn{2}{|c||}{} & $\rho$ & $C^{2}$ & $E\left\{D^{3}\right\}$ & Error \\
\hline \multicolumn{2}{|c|}{ Exact Value } & $8.229793 \mathrm{E}-1$ & $1.007901 \mathrm{E}+1$ & $3.717445 \mathrm{E}+3$ & \\
\hline \hline \multirow{3}{*}{ Model 1a } & $\left(1^{\text {tt }}\right.$ root of $\left.\alpha\right)$ & $8.229793 \mathrm{E}-1$ & $1.007901 \mathrm{E}+1$ & $3.716958 \mathrm{E}+3$ & $5.567303 \mathrm{E}-4$ \\
\cline { 2 - 6 } & $\left(2^{\text {nd }}\right.$ root of $\left.\alpha\right)$ & \multicolumn{4}{|c|}{ Not Feasible Solution } \\
\cline { 2 - 6 } & $\left(1^{\text {st }}\right.$ root of $\left.\alpha\right)$ & $8.229793 \mathrm{E}-1$ & $1.007901 \mathrm{E}+1$ & $3.717365 \mathrm{E}+3$ & $5.444864 \mathrm{E}-4$ \\
\cline { 2 - 6 } & $\left(2^{\text {nd }}\right.$ root of $\left.\alpha\right)$ & \multicolumn{4}{|c|}{ Not Feasible Solution } \\
\hline Model 2a & $($ Matching $\rho)$ & $8.229793 \mathrm{E}-1$ & $1.008115 \mathrm{E}+1$ & $3.718165 \mathrm{E}+3$ & $5.679044 \mathrm{E}-4$ \\
Model 2b & $\left(\right.$ Matching $\left.C^{2}\right)$ & $8.227858 \mathrm{E}-1$ & $1.007901 \mathrm{E}+1$ & $3.719068 \mathrm{E}+3$ & $3.123935 \mathrm{E}-4$ \\
\hline Model 3a & (Distribution) & $8.229793 \mathrm{E}-1$ & $1.007901 \mathrm{E}+1$ & $3.717462 \mathrm{E}+3$ & $5.415253 \mathrm{e}-4$ \\
Model 3b & $\left(E\left\{D^{3}\right\}\right)$ & $8.229793 \mathrm{E}-1$ & $1.007901 \mathrm{E}+1$ & $3.725824 \mathrm{E}+3$ & $2.949322 \mathrm{E}-4$ \\
\hline
\end{tabular}

Table 8: Arrival Process $\left(p_{A}=0.999, q_{A}=0.988, \alpha_{A}=0.9\right), \sigma=0.1, \mathrm{~K}=10$

\begin{tabular}{|c|c||c|c|c|c|}
\hline \multicolumn{2}{|c||}{} & \multicolumn{4}{c|}{ Departure Process } \\
\cline { 3 - 6 } & $\rho$ & $C^{2}$ & $E\left\{D^{3}\right\}$ & Error \\
\hline \multicolumn{2}{|c||}{ Exact Value } & $7.613183 \mathrm{E}-1$ & $3.909688 \mathrm{E}+2$ & $3.373541 \mathrm{E}+6$ & \\
\hline \hline \multirow{3}{*}{ Model 1a } & $\left(1^{\text {st }}\right.$ root of $\left.\alpha\right)$ & $7.613183 \mathrm{E}-1$ & $3.909688 \mathrm{E}+2$ & $3.373439 \mathrm{E}+6$ & $1.013476 \mathrm{E}-5$ \\
\cline { 2 - 6 } & $\left(2^{\text {nd }}\right.$ root of $\left.\alpha\right)$ & \multicolumn{4}{c|}{ Not Feasible Solution } \\
\cline { 2 - 6 } Model 1b & $\left(1^{\text {ot }}\right.$ root of $\left.\alpha\right)$ & $7.613183 \mathrm{E}-1$ & $3.909688 \mathrm{E}+2$ & $3.373582 \mathrm{E}+6$ & $3.755092 \mathrm{E}-5$ \\
\cline { 2 - 7 } & $\left(2^{\text {nd }}\right.$ root of $\left.\alpha\right)$ & \multicolumn{4}{c|}{ Not Feasible Solution } \\
\hline Model 2a & (Matching $\rho)$ & $7.613183 \mathrm{E}-1$ & $3.909993 \mathrm{E}+2$ & $3.373846 \mathrm{E}+6$ & $2.187076 \mathrm{E}-5$ \\
Model 2b & $\left(\right.$ Matching $\left.C^{2}\right)$ & $7.612587 \mathrm{E}-1$ & $3.909688 \mathrm{E}+2$ & $3.374110 \mathrm{E}+6$ & $1.190766 \mathrm{E}-4$ \\
\hline Model 3a & $($ Distribution $)$ & $7.613183 \mathrm{E}-1$ & $3.909688 \mathrm{E}+2$ & $3.373545 \mathrm{E}+6$ & $5.881160 \mathrm{E}-7$ \\
Model 3b & $\left(E\left\{D^{3}\right\}\right)$ & $7.613183 \mathrm{E}-1$ & $3.909688 \mathrm{E}+2$ & $3.373545 \mathrm{E}+6$ & $5.881123 \mathrm{E}-7$ \\
\hline
\end{tabular}

Table 9: Arrival Process $\left(p_{A}=0.99989, q_{A}=0.9994, \alpha_{A}=0.999\right), \sigma=0.1, \mathrm{~K}=10$ 


\section{Analysis of a Tandem Configuration with Cell Loss}

In this section, we analyze approximately a tandem configuration of discrete-time finite capacity queues using the fitting models described in the previous section. Let us consider an open queueing network consisting of $N$ nodes linked in tandem as shown in figure 4 . The nodes are numbered from 1 to $N$ starting from the leftmost node. We assume that each node has a finite capacity. Let $K_{i}$ be the maximum capacity of node $i, i=1,2, \cdots, N$. A cell enters a node if it arrives at a time when the node is not full. Otherwise, it gets lost. The arrival process to the first node is assumed to be an IBP. For each node $i$, the service time is assumed to be geometrically distributed with probability $\sigma_{i}$. We note that the $N$ servers are not synchronized. That is, the service slots of a server begin at a different time than the service slots of the other servers. However, all service slots of all servers are equal. Finally, we assume that cells in a node are served in a FIFO manner.

The approximation algorithm decomposes the queueing network into individual nodes, and each node is analyzed in isolation. Let us consider node $i$. We can obtain the generating function of the interdeparture time of node $i$ using equation (11). Using one of the fitting models mentioned above, we can then obtain the set of parameters $\{p, q, \alpha\}$ of an IBP which characterizes approximately the departure process of node $i$. This IBP becomes the arrival process to the next down-stream node $i+1$. Since the arrival process to node $i+1$ is modeled as an IBP, node $i+1$ can also be analyzed as an IBP $/ \mathrm{Geo} / 1 / K_{i+1}$ queue. In the examples given below, each queue is analyzed numerically using the Gaussian elimination method. In this manner, we can analyze all queues individually starting from the first node and proceeding sequentially to the last node. A summary of the algorithm is given below.

step $0:$ Set $i=1$.

step 1: Obtain the queue length distribution and the cell loss probability at node $i$. If $i<N$, go to step 2. Else, stop.

step 2: Compute the generating function of the distribution of the interdeparture time of node $i$. From the generating function, calculate $\rho, C^{2}$ and third moment.

step 3 : Using a fitting model, characterize approximately the departure process as an IBP. 


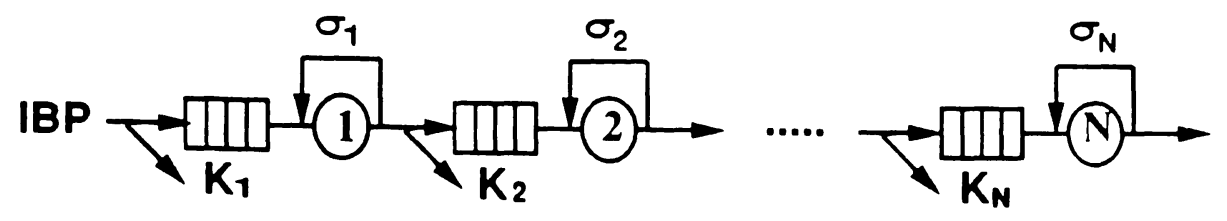

Figure 4: An open tandem queueing network under investigation

step 4: Set $i=i+1$ and go to step 1 .

The accuracy of the approximation algorithm was tested by analyzing a 10 node tandem configuration. Two different examples were considered, one corresponding to a case of small buffers and the other to a case of large buffers. The parameters of the arrival process to the first node for the two examples are given in Table 10. The values of $K_{i}$ and $\sigma_{i}$ for example 1 are: $K_{i}=5$ for $i=1,3,4,7,8,9, K_{i}=10$ for $i=2,5,6,10, \sigma_{i}=0.1$ for $i=1,3,4,6,7,8,9$, and $\sigma_{i}=0.2$ for $i=5,10$. The values of $K_{i}$ and $\sigma_{i}$ for example 2 are: $K_{i}=32$ and $\sigma_{i}=0.1$ for $i=1,2, \cdots, 10$. The approximation results were compared against simulation data in Figures 5-15. In particular, figures 5-10 are for example 1, and figures 11-15 for example 2.

The approximate results for example 1 were obtained using model 2a. (Model $3 \mathrm{~b}$ was also used but it gave identical results. The estimated squared coefficient of variation of the interdeparture time, however, obtained using model $2 \mathrm{a}$ has a slightly larger relative error than that of model $3 \mathrm{~b}$.$) In Figure 5$ we give the queue length distribution for nodes 2, 5, and 10. In Figure 7 we give the $\operatorname{Pr}\{$ empty $\}, \operatorname{Pr}\{$ full $\}$, and cell loss for each queue. The cell loss probability at a node is

$$
\operatorname{Pr}\{\text { Node is full } \mid \text { an arrival occurs }\}=\frac{P(0, K)\left(1-q_{A}\right) \alpha_{A}+P(1, K) p_{A} \alpha_{A}}{\sum_{n=0}^{K}\left[P(0, n)\left(1-q_{A}\right) \alpha_{A}+P(1, n) p_{A} \alpha_{A}\right]}
$$

Finally, in Figure 9 we give the throughput and squared coefficient of variation of the interdeparture time for each node. Relative errors are given in Figures 6, 8, and 10 . We note that the confidence intervals were not plotted as they were extremely small. Also, the large relative errors observed in some of the plots are for approximate and simulation values which 


\begin{tabular}{|c|c||c|c|}
\hline \multirow{2}{*}{ Example } & \multicolumn{3}{|c|}{ Arrival Process } \\
\cline { 2 - 4 } & parameters & $\rho$ & $C^{2}$ \\
\hline \multirow{3}{*}{1} & $p_{A}=9.999000 \mathrm{E}-1$ & & \\
& $q_{A}=4.999000 \mathrm{E}-1$ & $9.098181 \mathrm{E}-2$ & $9.054549 \mathrm{E}-2$ \\
& $\alpha_{A}=8.000000 \mathrm{E}-1$ & & \\
\hline \multirow{3}{*}{2} & $p_{A}=9.998900 \mathrm{E}-1$ & & \\
& $q_{A}=9.994000 \mathrm{E}-1$ & $8.442254 \mathrm{E}-1$ & $4.358311 \mathrm{E}+2$ \\
& $\alpha_{A}=9.990000 \mathrm{E}-1$ & & \\
\hline
\end{tabular}

Table 10: The arrival processes

are extremely small (i.e. less than $10^{-3}$ ).

The approximate results for example 2 are given in Figures 11- 15. These results are presented in the same way as in example 1 . Model $2 a, 3 b$, and a combination of models $1 a$ and 2a were used. Models 1a and 2a were combined as follows: use model 1a if it gives a feasible solution. If the solution is not feasible, then use model $2 a$. The results obtained using these fitting models are identical. (The estimated squared coefficient of variation of the interdeparture time was the same for all models.) In view of this, we are only present the results obtained using model $2 a$.

In general, all fitting models give about the same accuracy. Model 3 gives the best estimate for the distribution of the interdeparture time of each queue but it is time consuming. The other models, such as model $2 \mathrm{a}$ or the combined models $1 \mathrm{a}$ and $2 \mathrm{a}$, can give better estimates for the queue-length distribution or the cell loss probability. As mentioned earlier, model $2 a$ gives estimates of the squared coefficient of variation of the interdeparture time that has a larger relative error than those obtained using other models. The combined method of model 1a and $2 a$ seems to provide the best approach as it has a satisfactory accuracy and it is computationally efficient. 


\section{Conclusion}

In this paper, we proposed various models for characterizing the interdeparture time of a discrete-time IBP/Geo/1/K queue by an IBP. We applied these models to analyze a tandem configuration of discrete-time finite capacity queues with customer loss. 


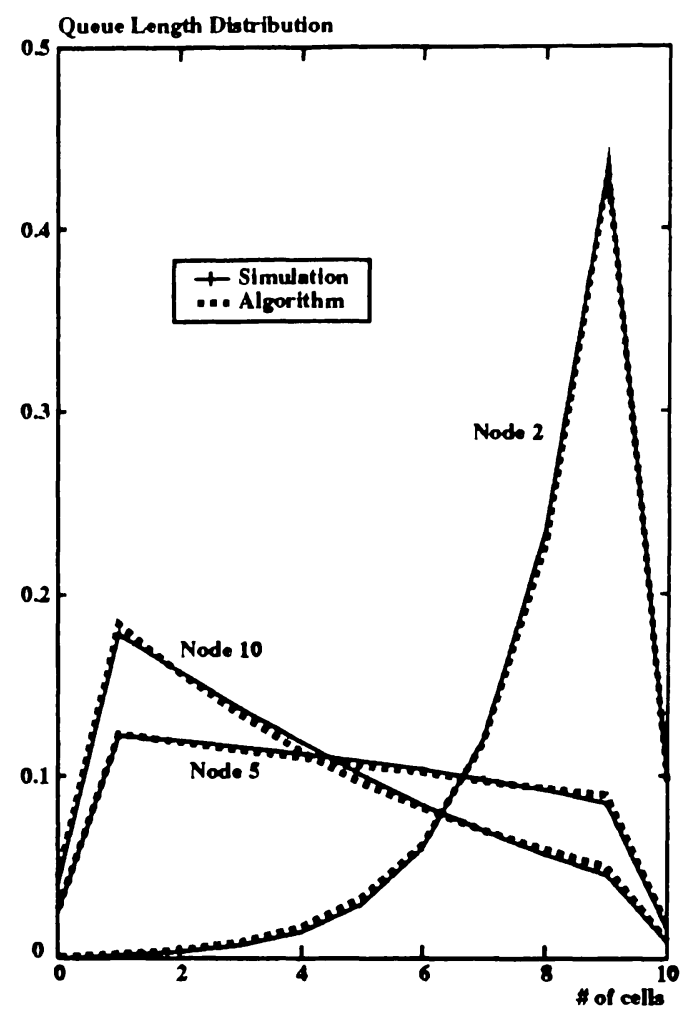

Figure 5: Queue length distribution (example 1)

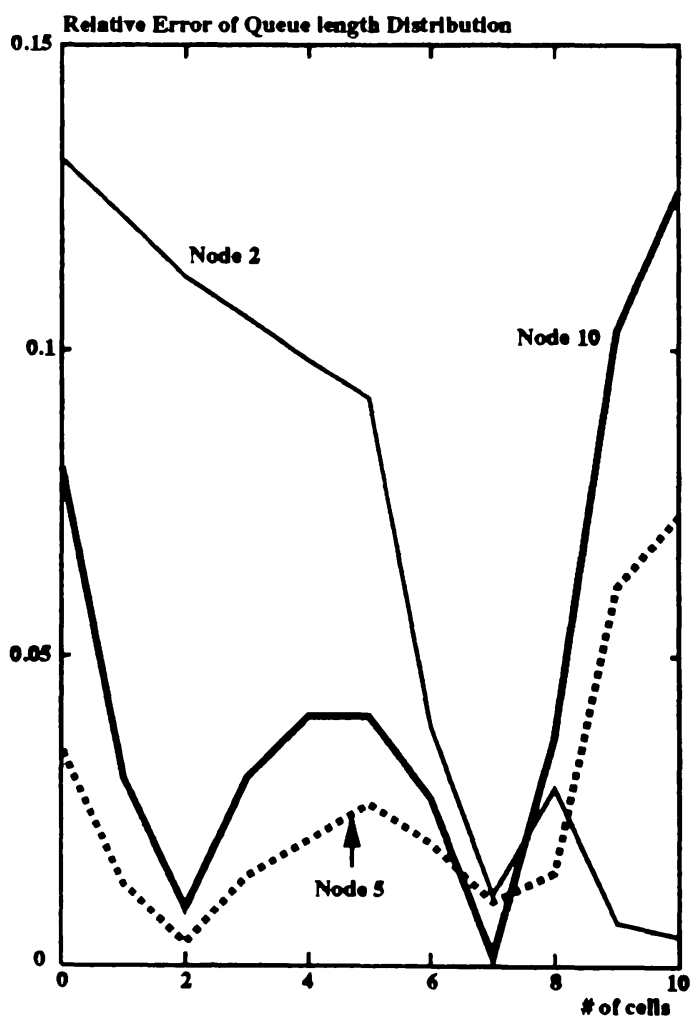

Figure 6: Relative error for results in Figure 5. 


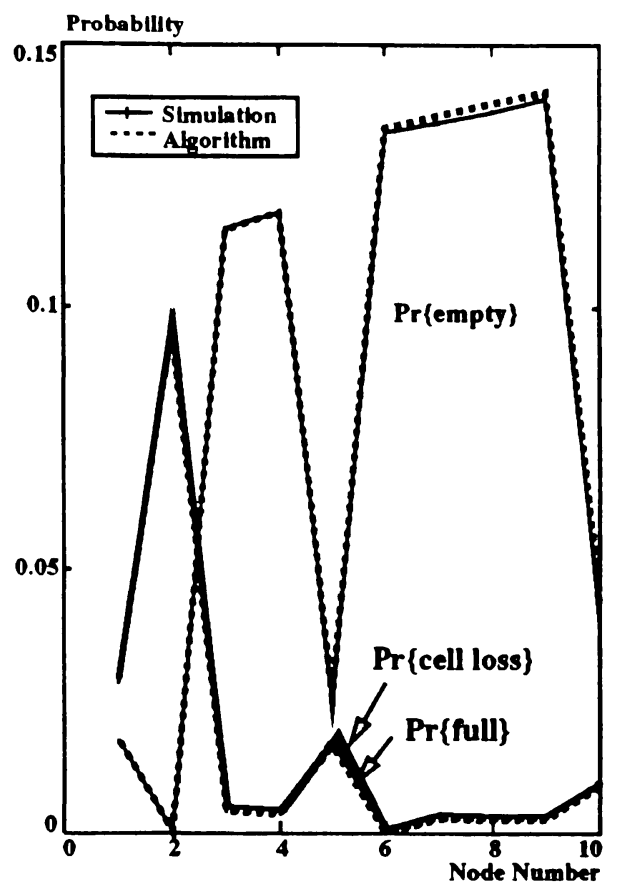

Figure 7: $\operatorname{Pr}\{$ empty $\}, \operatorname{Pr}\{$ full $\}$, and $\operatorname{Pr}\{$ cell loss $\}$ (example 1)

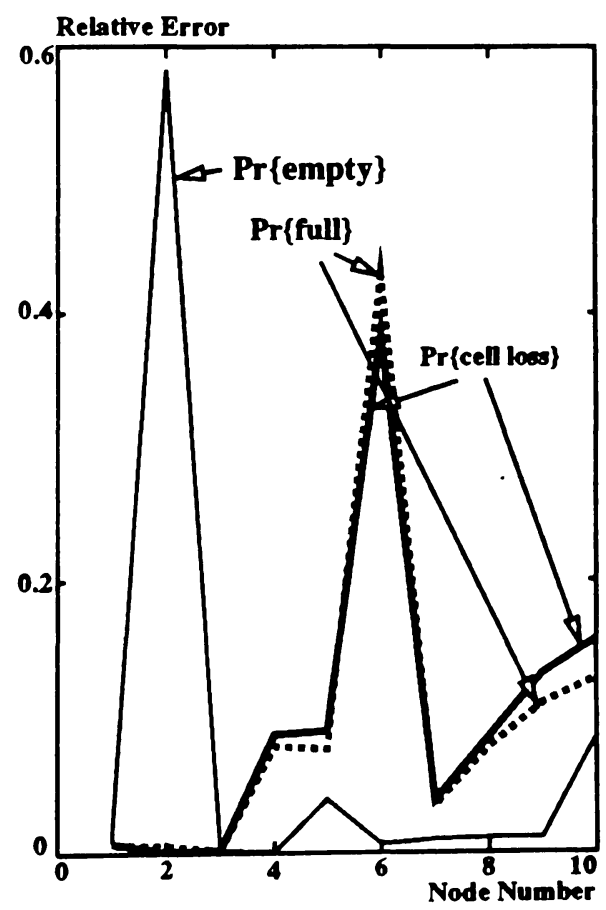

Figure 8: Relative error for results in Figure 7. 


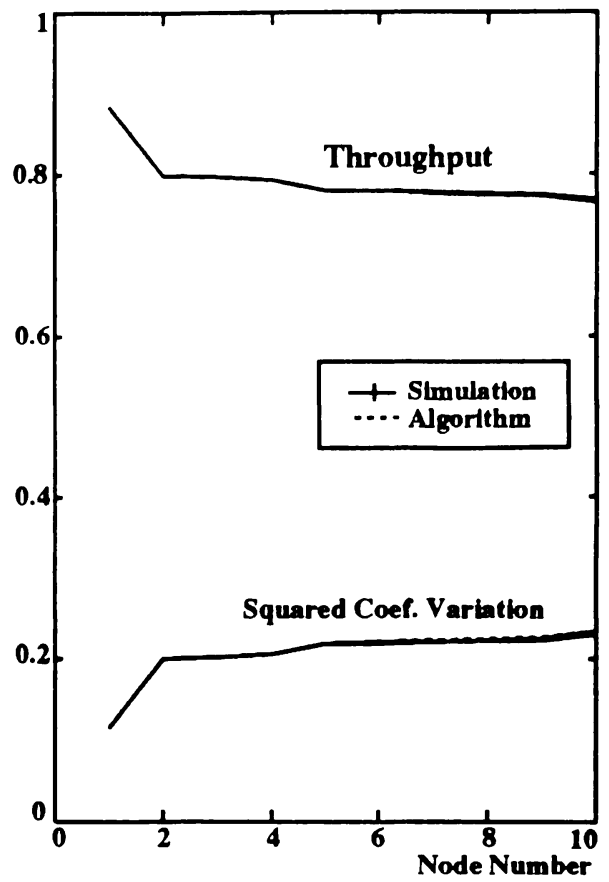

Figure 9: Throughput and squared coefficient of variation (example 1)

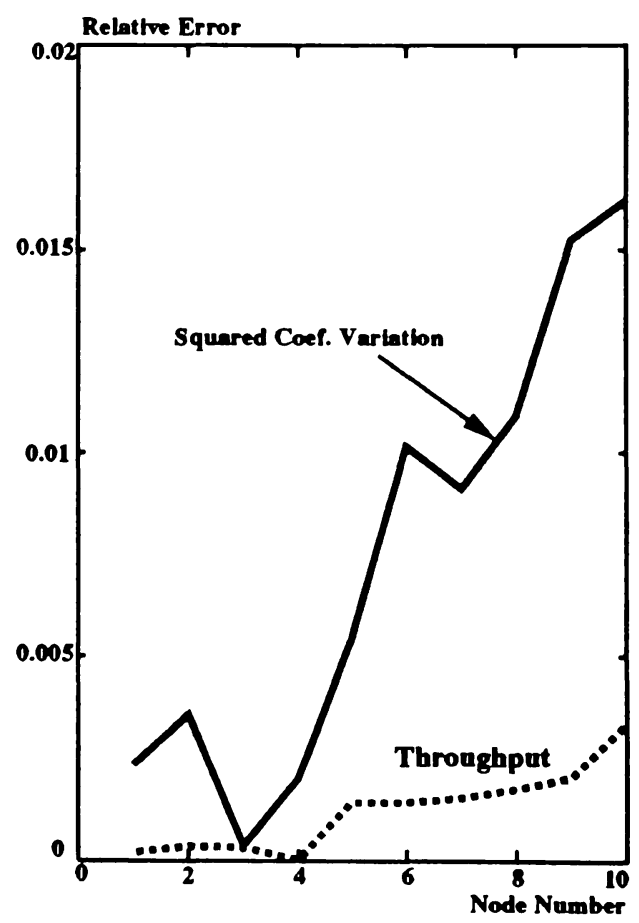

Figure 10: Relative error for results in Figure 9. 


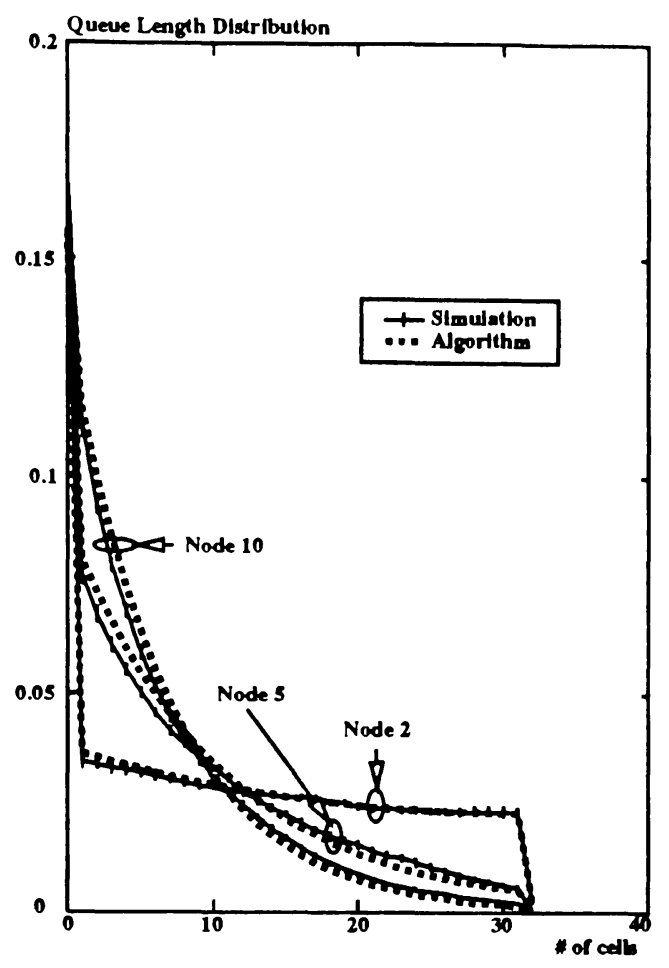

Figure 11: Queue Length Distribution (example 2)

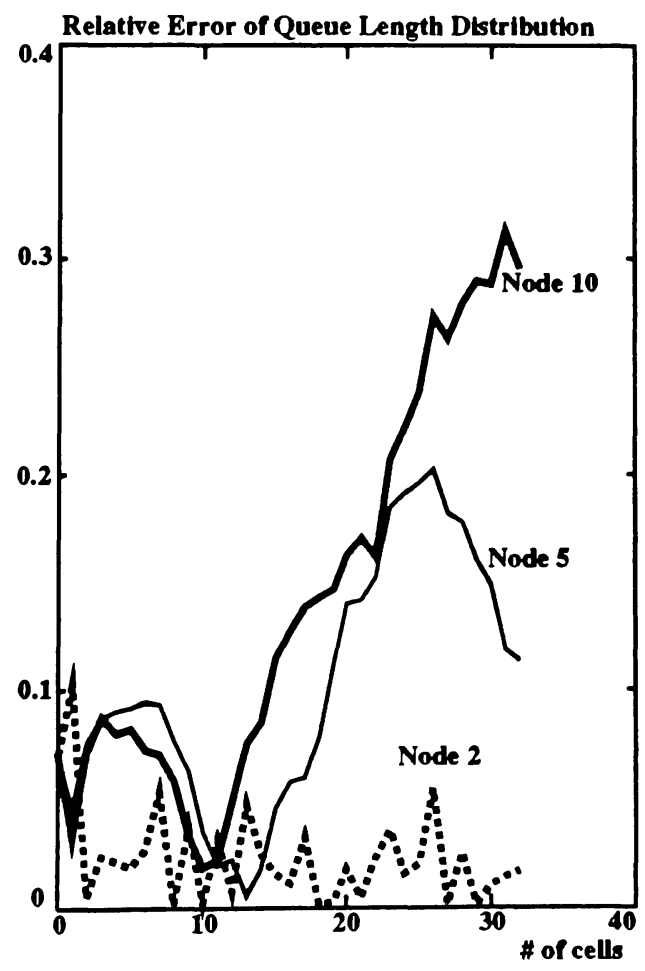

Figure 12: Relative error for results in Figure 11. 


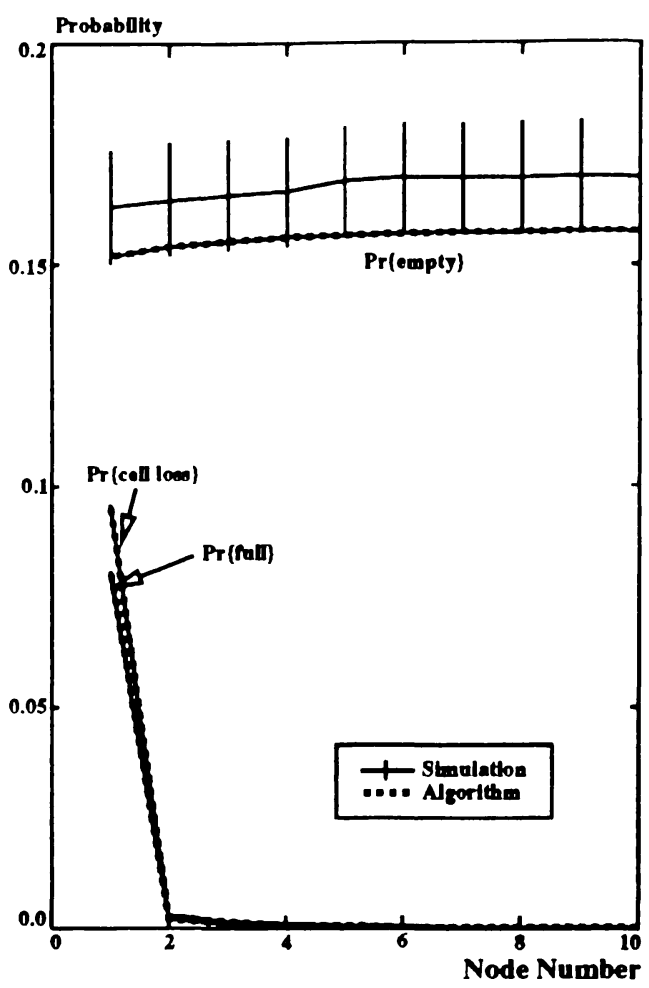

Figure 13: $\operatorname{Pr}\{$ empty $\}, \operatorname{Pr}\{$ full $\}$, and $\operatorname{Pr}\{$ cell loss $\}$ (example 2)

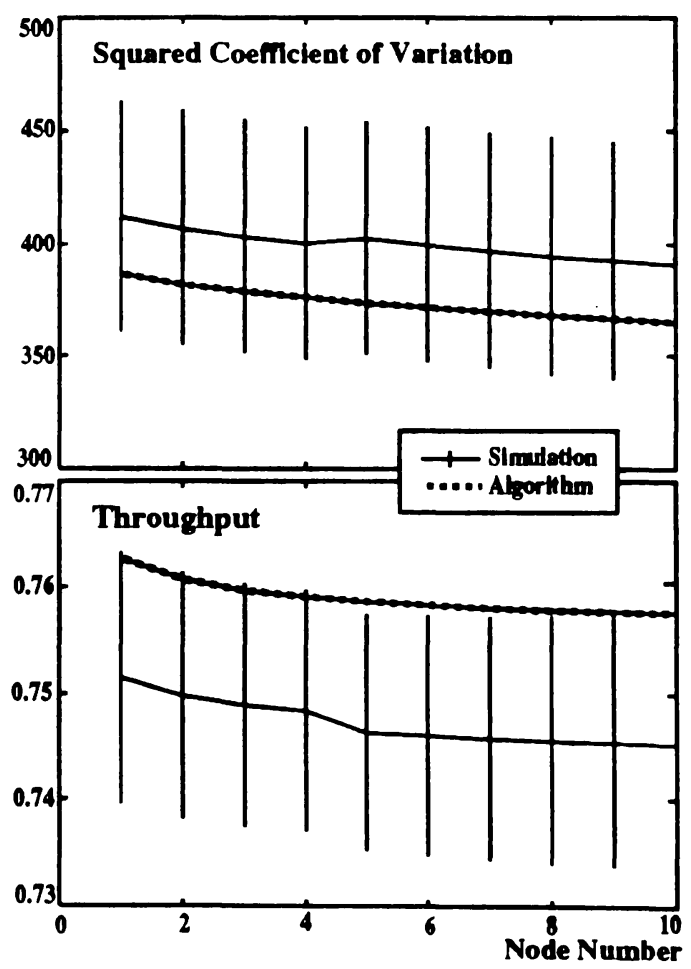

Figure 14: Throughput and squared coefficient of variation (example 2) 


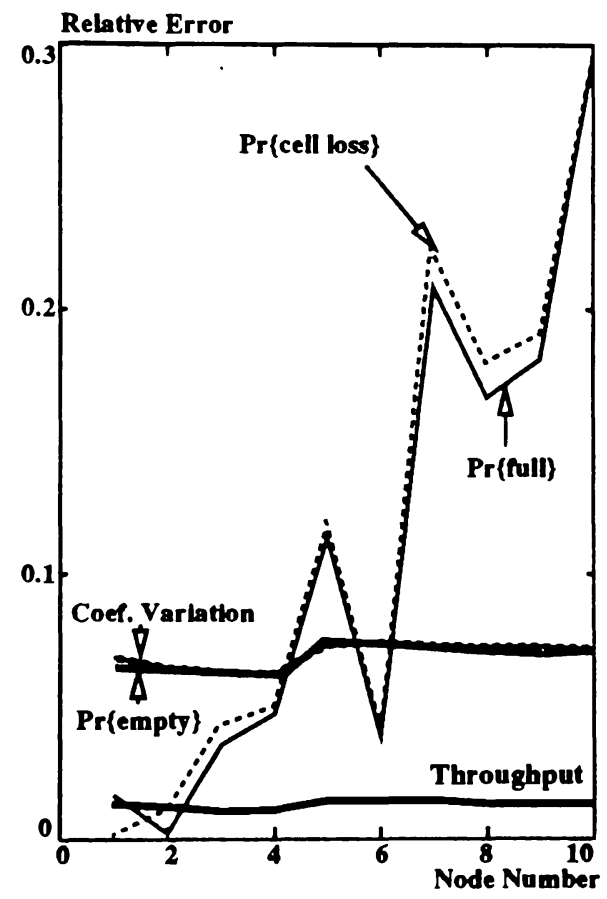

Figure 15: Relative error for results in Figure 13 and 14. 


\section{A Appendix}

Given a value of $\alpha$, where $0<\alpha \leq 1$, we can obtain the following solution for $p$ and $q$ (see section 4.3).

$$
\begin{aligned}
& p=\frac{\left(C^{2}-1\right) \alpha+3 \alpha \rho-2 \rho^{2}}{\left(C^{2}-1\right) \alpha-\alpha \rho+2 \alpha^{2}} \\
& q=\frac{\left(C^{2}-1\right) \alpha-3 \alpha \rho+2 \alpha^{2}+2 \rho^{2}}{\left(C^{2}-1\right) \alpha-\alpha \rho+2 \alpha^{2}}
\end{aligned}
$$

we show that if conditions (1) to (3) hold then $0<$ p $<1$ and $0<q<1$.

(a) If $\left(C^{2}-1\right) \alpha+3 \alpha \rho-2 \rho^{2}>0$ then $0<p<1$.

proof:

Since the following relation

$$
\left[\left(C^{2}-1\right) \alpha-\alpha \rho+2 \alpha^{2}\right]-\left[\left(C^{2}-1\right) \alpha+3 \alpha \rho-2 \rho^{2}\right]=2(\alpha-\rho)^{2}>0
$$

is always true, we have that the relation,

$$
\left(C^{2}-1\right) \alpha-\alpha \rho+2 \alpha^{2}>\left(C^{2}-1\right) \alpha+3 \alpha \rho-2 \rho^{2}>0
$$

is also always true if $\left(C^{2}-1\right) \alpha+3 \alpha \rho-2 \rho^{2}>0$. Since the numerator and denominator in equation (23) are all positive and the denominator is larger than the nominator, we have that $0<p<1$.

(b) If $\left(C^{2}-1\right) \alpha-3 \alpha \rho+2 \rho^{2}+2 \alpha^{2}>0$ and and $\rho<\alpha \leq 1$ then $0<q<1$.

proof:

If can be easily shown that following relation

$$
\left(C^{2}-1\right) \alpha-3 \alpha \rho+2 \rho^{2}+2 \alpha^{2}<\left(C^{2}-1\right) \alpha-\alpha \rho+2 \alpha^{2}
$$

is true if $\rho<\alpha$. Hence, if $\rho<\alpha$ and $\left(C^{2}-1\right) \alpha-3 \alpha \rho+2 \rho^{2}+2 \alpha^{2}>0$ then $0<q<1$. 


\section{REFERENCES}

[1] A. Bhargava, J. Kurose, D. Towsley, and G. Vanleemput. Performance comparison of error control schemes in high-speed computer communication network. IEEE J. Select. Areas Commun., (9), Dec. 1988.

[2] P. P. Bocharov and F. K. Albores. On two-stage exponential queueing system with internal losses or blocking. Prob. Control Inform. Theory, 1980.

[3] J. Hsu and P. Burke. Behavior of tandem buffers with geometric input and Markovian output. IEEE Trans. Commun., Mar. 1976.

[4] H. Kobayashi, Modeling and Analysis: An introduction to system performance evaluation methodology. Reading, MA: Addison-Wesley Publishing Company, 1978.

[5] T. D. Morris and H. G. Perros. Performance analysis of a multi-buffered Banyan ATM switch under bursty traffic. to be presented in INFOCOM ' 91 .

[6] J. Morrison. Two discrete-time queues in tandem. IEEE Trans. Commun., (3):563-573, Mar. 1979.

[7] A. Nilsson, F. Lai, and H. G. Perros. An approximate analysis of a bufferless $\mathrm{N} \times \mathrm{N}$ synchronous class ATM switch. In Queueing Performance and Control in ATM. Cohen, and Pack, Eds. North Holland, 1991.

[8] Y. Ohba, M. Murata, and H. Miyahara. Analysis of interdeparture process for bursty traffic in ATM networks. IEEE J. Select. Areas Commun., (3), Apr. 1991.

[9] G. Pujolle. Multiclass distrete-time queueing systems with a product form solution. Int'l. Seminar on the Performance of Distributed and Parallel Systems, Sept. 1991.

[10] G. Pujolle and H. G. Perros. Queueing systems for modelling ATM networks. Proc. of the Int'l. Conf. on the Performance of Distributed Systems and Integrated Comm. Networks, Kyoto, Sept. 1991.

[11] P. Tran-Gia. Discrete time analysis for the interdeparture distribution of GI/G/1 queue. In Teletraffic Analysis and Computer Performance Evaluation, pages 341-357. O. J. Boxma, J. W. Cohen, and H.C. Tijms, Eds. North Holland:Elsevier Science, 1986. 